\title{
Optimization of Culture Conditions and Medium Components for Carboxymethyl Cellulase(CMCase) Production by a Novel Basidiomycete Strain Peniophora sp. NDVN01
}

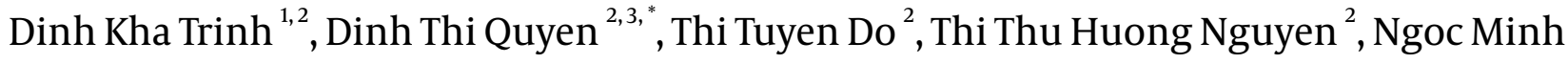 \\ Nghiem $^{2}$ \\ ${ }_{2}^{1}$ Department of Life Science, College of Sciences, Thai Nguyen University, Quyetthang Commune, Thai Nguyen, Vietnam \\ 2 Institute of Biotechnology, Vietnam Academy of Science and Technology, 18 Hoang Quoc Viet Road, Caugiay Distrist, 10600 Hanoi, Vietnam \\ 3 Department of Biotechnology and Pharmacology, University of Science and Technology of Hanoi, Hanoi, Vietnam \\ *Corresponding author: Dinh Thi Quyen, Institute of Biotechnology, Vietnam Academy of Science and Technology, 18 Hoang Quoc Viet Road, Caugiay Distrist, 10600 Hanoi, Vietnam, \\ Tel: + 84-0437568260, Fax: + 84-0438363144, E-mail: quyen@ibt.ac.vn; quyen-dinh.thi@usth.edu.vn
}

Received: March 04, 2013; Revised: July 26, 2013; Accepted: August 26, 2013

\begin{abstract}
Background: Cellulytic enzymes including Carboxymethyl cellulases play the key role in hydrolysis of cellulose, a huge organic carbon reservoir on earth, into monomeric sugars and their eventual conversion into valuable chemicals and energy sources.

Objectives: In this study, we described the identification of a basidiomycete isolate NDVN01 and optimization of culture conditions and medium components for CMCase production by this strain under liquid state fermentation. The CMCase was estimated as $32-33 \mathrm{kDa}$ on a native Polyacrylamide gel electrophoresis (PAGE).

Materials and Methods: We used 5 basidiomycetes for screening CMCase production, internal transcribed spacer(ITS) sequence analysis in combination with morphology for strain identification, and liquid state fermentation for optimization of CMCase production.

Results: The maximum CMCase production by Peniophora sp. NDVN01 was obtained at $28^{\circ} \mathrm{C}$, with the initial medium pH of 7 and within 120 hours of cultivation in the optimum medium containing $80 \%(\mathrm{v} / \mathrm{v})$ of potato infusion, $0.6 \%(\mathrm{w} / \mathrm{v})$ straw rice as additional carbon source and $0.2 \%(\mathrm{w} / \mathrm{v})$ ammonium hydrogen phosphate as an additional nitrogen source, and $0.5 \%(\mathrm{w} / \mathrm{v})$ pulp as inducer.

Conclusions: Under optimal conditions, Peniophora sp. NDVN01 produced $24.65 \pm 0.37$ units of CMCase per mL of culture supernatant, which was 8.6 times higher than the amount $\left(2.87 \pm 0.28 \mathrm{U}_{\mathrm{mL}}{ }^{-1}\right)$ before optimization.
\end{abstract}

Keywords: CMCase Culture Condition; Medium Component; Optimization; Peniophora sp. NDVN01

\section{Background}

Cellulose is a polymer of glucose, linked by beta-1,4-glycosidic bonds. Annual production of cellulose of about 180 billion tons makes this polysaccharide as a huge organic carbon reservoir on earth (1). It is used in different industries including production of paper, clothes, food additives, and ruminant nutrients. Recently, due to identification of cellulose-degrading enzymes, or cellulases, cellulose has emerged as a renewable source of energy with enormous potential (2). The cellulose-degrading enzymes play the key role in the biological conversion of cellulosic biomass to valuable biofuels and chemicals (3). Cellulase is a complex family comprising of three groups of hydrolytic enzymes including endo-(1,4)- $\beta$-D- glucanase [endoglucanase (EG), endocellulase, CMCase (EC 3.2.1.4)], exo-(1,4)- $\beta$-D-glucanase [exoglucanase, cellobiohydrolase, exocellulase, microcrystalline cellulase, avicelase (EC 3.2.1.91)], and finally, $\beta$-glucosidase [cellobiase, (EC 3.2.1.21)]. Endoglucanases act randomly on soluble and insoluble cellulose chains while exoglucanases act to remove cellobiose from the reducing and non-reducing ends of cellulose chains, and glucosidases remove glucose from cellobiose (2). The synergistic action of these three enzyme groups with different functions is required for the complete hydrolysis of cellulose (4). The cellulases make us possible to utilize cellulosic biomass in an environmentally friendly manner (5).

CMCases have a broad variety of applications in detergent and animal feed production (6), in the textile

Implication for health policy / practice / research / medical education:

Cellulases have a broad application in biodegradation of natural celluloses (rice straw, sugarcane bagasse, corn cob, stalk, etc.) to produce bioethanol, thus to produce novel cellulases with better properties are the aim of many studies. This study focused on identification of a new basidiomycete isolate NDVN01 and optimization of the culture conditions and medium components for the CMCase production by the basidoomycete Peniophora sp. NDVN01 under liquid state fermentation.

Copyright (c) 2013, National Institute of Genetic Engineering and Biotechnology; Published by Kowsar Corp. This is an Open Access article distributed under the terms of the Creative Commons Attribution License (http: // creativecommons.org/ licenses / by / 3.0), which permits unrestricted use, distribution, and reproduction in any medium, provided the original work is properly cited. 
industry, pulp and paper industry, starch, grain alcohol fermentation, malt and beer production, extraction of fruit and vegetable juices (7), production of organic solvents (8). However, in many bioconversion strategies, the cellulases required for biomass conversion may still account for as much as $40 \%$ of the total process cost (9). Thus, large-scale and low-cost production of cellulase is a significant key for the overall process economics of lignocellulosics bioconversion.

A large number of microorganisms including bacteria, actinomycetes and fungi $(10,11)$ are capable to produce CMCases. Among fungi, many basidiomycetes including Volvariella volvacea $(12,13)$, Fomitosis sp. (14-16), Lentinus edodes (17), Irpex lacteus (18), Bjerkandera adusta and Pycnoporus sanguineus (19) have been studied for the CMCase production. In this study, for the first time, we described the identification of a novel basidiomycete isolate NDVNO1 and optimization of culture conditions and medium components for the CMCase production by the basidiomycete Peniophora sp. NDVN01 under liquid state fermentation.

\section{Objectives}

In this study, for the first time, we described the identification of a novel basidiomycete isolate NDVN01 and optimization of culture conditions and medium components for the CMCase production by the basidiomycete Peniophora sp. NDVN01 under liquid state fermentation.

\section{Materials and Methods}

\subsection{Strains and Culture Conditions}

Five basidiomycete strains, Peniophora sp. NDVN01, Pleurotus sajor-caju, Pleurotus ostreatus, Ganoderma lucidum, Flammulina velutipes were collected from the Culture Collection of the Laboratory of Biology, Department of Life Science, College of Sciences, Thai Nguyen University, Vietnam. Peniophora sp. NDVN01 was identified based on morphology and on the sequence variation region containing $18 \mathrm{~S}$ ribosomal RNA (partial sequence), internal transcribed spacer $1,5.8 \mathrm{~S}$ ribosomal RNA, internal transcribed spacer 2 (complete sequence), and $28 \mathrm{~S}$ ribosomal RNA (partial sequence).

Peniophora sp. NDVN01 was maintained on PDA slant at $4{ }^{\circ} \mathrm{C}$ and sub-cultured on fresh sterile PDA slant and incubated for 7 days. The strain was grown in $100 \mathrm{~mL} \mathrm{Er}$ lenmeyer flasks containing $30 \mathrm{~mL}$ of basal medium at 30 ${ }^{\circ} \mathrm{C}$ and on an orbital shaker with $200 \mathrm{rpm}$ for CMCase production. The basal medium contained $20 \%(\mathrm{v} / \mathrm{v})$ potato infusion and $0.6 \%(\mathrm{w} / \mathrm{v})$ pulp, adjusted to $\mathrm{pH}$. Two hundreds gram of peeled and sliced potatoes were boiled in 1 L of distilled water for 30 mins and then filtered through cheesecloth to obtain potato infusion. The culture supernatant harvested by centrifugation at $10000 \mathrm{rpm}$ and 4
${ }^{\circ} \mathrm{C}$ for 10 mins, was used for determination of CMCase activity.

\subsection{Chemicals}

Carboxymethyl cellulose from Biochemika (Sigma Aldrich Co., St. Luis, USA), peptone and yeast extract from Bio Basic Inc. (Ontario, Canada), 3,5-dinitrosalicyclic acid (DNS) from Fluka (Sigma Aldrich Co., St. Luis, USA). Escherichia coli DH10B, PJET1.2 / blunt vector, T4 ligase, and Taq polymerase (Fermentas, Thermo Fisher Scientific Inc., Waltham, USA) were used for DNA manipulations and amplification. All other reagents were of analytical grade unless otherwise stated.

\subsection{Identification of the Fungus}

Isolation of genomic DNA: Fungal isolate NDVN01 was grown on PDA at $30{ }^{\circ} \mathrm{C}$ with agitation of $200 \mathrm{rpm}$ for 5 days. $30 \mathrm{~mL}$ of the culture was harvested by centrifugation at $10000 \mathrm{rpm}$ and $4{ }^{\circ} \mathrm{C}$ for $10 \mathrm{mins}$. The fungal mycelium was ground in liquid nitrogen to produce a fine powder, it was transferred to a fresh $2 \mathrm{~mL}$ tube, added with $600 \mu \mathrm{L}$ of cell lysis buffer and $50 \mu \mathrm{L}$ protease $\mathrm{K}(200$ mg.mL ${ }^{-1}$ ) and incubated at $56^{\circ} \mathrm{C}$ for 3 hours with slightly hand shaking. $200 \mu \mathrm{L} 5 \mathrm{M}$ potassium acetate was added to the mixture and incubated on ice bath for 10 mins. After centrifugation at $10000 \mathrm{rpm}$ and $4{ }^{\circ} \mathrm{C}$ for $10 \mathrm{mins}$, the supernatant $(700 \mu \mathrm{L})$ containing genomic DNA was extracted using $700 \mu \mathrm{L}$ chloroform: isoamyl alcohol (24 :1) to destroy proteins and the upper phase $(500 \mu \mathrm{L})$ was added to $500 \mu \mathrm{L} 100 \%$ isopropanol to precipitate DNA. The DNA pellet was dissolved in TE buffer at $\mathrm{pH} 8$.

ITS sequence of the fungal isolate NDVNO1 was amplified by PCR using primer pairs as follow: ITS1F (5'-CTT GGT CAT TTA GAG GAA GTA A-3') and NL4 (5'-GGT CCG TGT TTC AAG ACG G-3'). The PCR mixture contained $2.5 \mu \mathrm{L}$ 10X PCR buffer; $2 \mu \mathrm{L}$ of $2 \mathrm{mM}$ dNTP; $2 \mu \mathrm{L}$ of $25 \mathrm{mM} \mathrm{MgCl} ; 1.5 \mu \mathrm{L}$ genomic DNA (50 - $100 \mathrm{ng}$ ); $0.25 \mu \mathrm{L} 5$ unit Taq polymerase and $1 \mu \mathrm{L}$ each primer (10 pmol), supplemented in 14.75 $\mu \mathrm{L}$ distilled water adjusted to a final volume of $25 \mu \mathrm{L}$. The thermocycler conditions were as follows: $95^{\circ} \mathrm{C} / 5$ '; 30 cycles of $\left(95^{\circ} \mathrm{C} / 1^{\prime}, 55^{\circ} \mathrm{C} / 1^{\prime}, 7{ }^{\circ} \mathrm{C} / 1^{\prime}\right) ; 7{ }^{\circ} \mathrm{C} / 10$ '. The PCR products amplified from the genomic DNA with both primer ITS1F and NL4 were inserted into the cloning vector PJET1.2 / blunt, resulting in pJITS and then sequenced. DNA sequencing was performed on ABI PRISM 3100 Avant Genetic Analyzer. Sequence obtained was compared with ITS sequences available in GenBank, using Clustal W method and a dendrogram was constructed to establish the taxonomic rank of the fungus (MegAlign DNAStar, Madison, WI, USA).

\subsection{Enzyme Assay}

CMCase activity was examined relatively by the halo radius of enzyme diffusion on agar plates containing $0.5 \%$ 
(w/v) CMC. After 120 hours of growth in the basal medium containing $0.5 \%(\mathrm{w} / \mathrm{v}) \mathrm{CMC}, 50 \mu \mathrm{L}$ of the culture supernatant was dropped into small holes ( $0.8 \mathrm{~cm}$ diameter) on agar plates and incubated at $4{ }^{\circ} \mathrm{C}$ for overnight for enzyme diffusion then at $37^{\circ} \mathrm{C}$ for 6 - 8 hours and stained with $1 \%(w / v)$ Lugol's solution.

The CMCase activity towards CMC was measured in terms of release of reducing sugars by DNS method (Miller 1959). The reaction mixture containing $0.25 \mathrm{~mL}$ of diluted enzyme and $0.5 \mathrm{~mL}$ of $1 \%$ (w/v) CMC in 100 $\mathrm{mM}$ sodium acetate buffer at $\mathrm{pH} 5$ was incubated at $50{ }^{\circ} \mathrm{C}$ for 10 mins and stopped by adding $0.75 \mathrm{~mL}$ of $1 \%$ $(\mathrm{w} / \mathrm{v})$ DNS reagent, followed by boiling for 10 mins. The mixture was cooled down at room temperature and developed color was read at $575 \mathrm{~nm}$ on a UV-2500 spectrophotometer (Labomed Inc., Culver City, California, USA). The blanks were prepared as the samples but DNS was added before CMC. Glucose was used as the standard reduced sugar for concentration estimation. One unit of CMCase activity is defined as the amount of enzyme that remove $1 \mu \mathrm{mol}$ glucose.min ${ }^{-1}$ under the standard assay conditions.

\subsection{Native Polyacrylamide Gel Electrophoresis}

To detect molecular mass and CMCase activity, native polyacrylamide gel electrophoresis (PAGE) was performed using $12.5 \%$ polyacrylamide gel (Laemmli 1970) containing $0.2 \% \mathrm{CMC}(\mathrm{w} / \mathrm{v})$ using Biometra equipment (Göttingen, Germany). The native gel was submerged in sterile distilled water for 30 mins and then in $1 \%(w / v)$ Triton X-100 for 1 hour at room temperature. The gel was then transferred into $50 \mathrm{mM}$ sodium acetate buffer at $\mathrm{pH}$ 4.5 for 30 mins and incubated overnight at room temperature. The gel was stained in a solution of $1 \%(\mathrm{w} / \mathrm{v})$ Congo Red for 30 mins, and destained in $1 \mathrm{M}$ sodium chloride for 15 mins. The activity band was clearly visible as yellowish clearances against a deep red background after 10 mins of destaining.

\subsection{Time Course of CMCase Production}

Time course of the CMCase production was varied from 24 to 216 hours at $28{ }^{\circ} \mathrm{C}$.

\subsection{Initial Medium $\mathrm{pH}$}

To determine initial medium $\mathrm{pH}$ optimum for the CMCase production, Peniophora sp. NDVN01 was grown in a $100 \mathrm{~mL}$ flask containing $30 \mathrm{~mL}$ of the basal medium at different $\mathrm{pH}$ ranges from 4 to 10 which was adjusted by using $1 \mathrm{~N} \mathrm{HCl}$ or $1 \mathrm{~N} \mathrm{NaOH}$.

\subsection{Culture Temperature}

To determine optimum temperature for the CMCase production, Peniophora sp. NDVN01 was grown at different temperature from 22 to $37^{\circ} \mathrm{C}$ on basal medium at $\mathrm{pH} 7$.

\subsection{Inducer Source and Concentration}

The effect of substrates as inducer including CMC, coffee outerskin, coir, corncob, peanut shells, rice straw, sawdust, and sugarcane bagasse at the concentration of $0.6 \%(\mathrm{w} / \mathrm{v})$ on CMCase production was studied. The concentration of the substrate as inducer for the highest CMCase production by Peniophora sp. NDVN01 was varied from 0.1 to $1 \%(w / v)$.

\subsection{Potato Infusion Concentration}

To determine the influence of potato infusion on the CMCase production, Peniophora sp. NDVN01 was grown in $100 \mathrm{~mL}$ shaking flasks containing $30 \mathrm{~mL}$ of the medium with potato infusion at various concentrations from 10 to $100 \%(\mathrm{v} / \mathrm{v})$, at $28{ }^{\circ} \mathrm{C}$ and $\mathrm{pH} 7$, with agitation of $200 \mathrm{rpm}$ for 120 hours.

\subsection{Carbon source and concentration}

The effect of various additional carbon sources including CMC, coffee outerskin, coir, corncob, peanut shells, rice straw, sawdust, sugarcane bagasse, galactose, glucose, lactose, mannose, sucrose, and xylose at the concentration of $0.2 \%(\mathrm{w} / \mathrm{v})$ on the CMCase production was studied. Peniophora sp. NDVN01 was grown in $100 \mathrm{~mL}$ shaking flasks containing $30 \mathrm{~mL}$ of the medium with 80 $\%$ of potato infusion, $0.5 \%$ paper pulp (w/v) and $0.2 \%(\mathrm{w} / \mathrm{v})$ of different carbon sources. The concentration of the carbon source giving the highest CMCase production varied from 0.1 to $1.4 \%(\mathrm{w} / \mathrm{v})$.

\subsection{Nitrogen Source and Concentration}

The effect of various additional nitrogen sources including beef extract, fish meal, meat extract, peptone, soybean meal, yeast extract, ammonium hydrogen phosphate, ammonium nitrate, ammonium sulphate, and potassium nitrate at the concentration of $0.2 \%(\mathrm{w} / \mathrm{v})$ was investigated. The concentration of the nitrogen giving the highest CMCase production varied from 0.1 to $1 \%(\mathrm{w} / \mathrm{v})$.

\subsection{Mineral Source and Concentration}

The effect of various mineral sources including $\mathrm{BaCl}_{2}$, $\mathrm{CaCO}_{3}, \mathrm{FeSO}_{4}, \mathrm{KCl}$, and $\mathrm{MgSO}_{4}$ at the concentrations of 0.05 to $0.2 \%(\mathrm{w} / \mathrm{v})$ was studied.

\subsection{Statistical Analysis}

All measurements were carried out in triplicate with the resulting values being the mean of the cumulative data obtained.

\section{Results}

4.1. Identification of the Fungus Peniophora sp. NDVN01 
Among 5 basidiomycetes, Peniophora sp. NDVN01 showed the highest CMCase production rate on agar plate containing $0.5 \%$ of CMC (Figure 1 ) and was selected for optimization of culture conditions and medium components for the CMCase production.

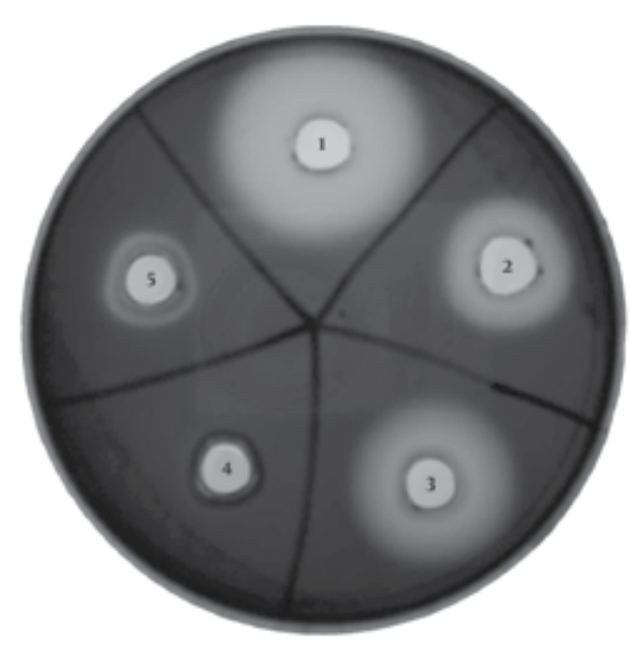

Figure 1. CMCase activity of several basidiomycetes. (1: Peniophora sp. NDVN01; 2: Pleurotus sajor-caju; 3: Pleurotus ostreatus; 4: Ganoderma lucidum; 5: Flammulina velutipes).

The basidiomycete isolate NDVN01 was identified based on the sequence variation region containing $18 \mathrm{~S}$ ribosomal RNA gene (partial sequence), internal transcribed spacer 1, 5.8S ribosomal RNA gene, internal transcribed spacer 2 (complete sequence), and $28 \mathrm{~S}$ ribosomal RNA gene (partial sequence). The ITS sequence consisted of 1255 bp from the basidiomycete isolate NDVN01 showed maximum identity of 93.7 to $99.2 \%$ with those from Peniophora strains (Figure 2).

Based on the morphological analyzes (data not shown) and the sequence variations present in internal transcribing spacer (ITS) region, the basidiomycete NDVN01 was identified as Peniophora and named as Peniophora sp. NDVN01. The sequence was deposited in GenBank with an accession number of JF925333 for Peniophora sp. NDVN01.

\subsection{Time Course of CMCase Production}

The CMCase production by Peniophora sp. NDVN01 increased slowly from $0.27 \pm 0.06$ U.mL ${ }^{-1}(12 \%)$ at 24 hours to $0.71 \pm 0.03 \mathrm{U}_{\mathrm{mL}}^{-1}(31 \%)$ at 72 hours, then linearly to the maximum of $2.32 \pm 0.07 \mathrm{U}_{\mathrm{mL}}^{-1}(100 \%)$ at 120 hours (5 days) of cultivation (Figure 3 ) and gradually decreased to $1.44 \pm 0.13 \mathrm{U}_{\mathrm{mL}}{ }^{-1}$ (62 \%) at 216 hours. On the native PAGE, the supernatant of Peniophora sp. NDVN01 showed a CMCase-activity stained band with a molecular mass of 32-33 kDa (Figure 4).

\subsection{Effect of Physiological Parameters on CMCase Production}

\subsubsection{Effect of Initial $p H$}

Initial medium $\mathrm{pH}$ is one of the most critical physical factors affecting both the mycelial growth and production of extracellular enzymes by microbial strains. The CMCase production by Peniophora sp. NDVN01 was influenced by the initial $\mathrm{pH}$ of the LSC medium, that gradually increased from $1.17 \pm 0.06 \mathrm{U}_{\mathrm{JmL}}^{-1}(45 \%)$ to the maximum of $2.62 \pm 0.17 \mathrm{U} \cdot \mathrm{mL}^{-1}(100 \%)$ at the initial pH of 7 (Figure 5 A). Increasing the initial medium $\mathrm{pH}$ from 7 to 10 showed a rapid decrease in the CMCase production to $0.39 \pm 0.05$ U.mL ${ }^{-1}(15 \%)$ (Figure 5 A).

\subsubsection{Effect of Temperature}

As initial medium $\mathrm{pH}$, temperature is one of the most important physical variable affecting both the mycelial growth and production of extracellular enzymes by microbial strains. The CMCase production by Peniophora sp. NDVN01 gradually increased from $2.25 \pm 0.14$ U.mL ${ }^{-1}(75 \%)$ to the maximum amount of $2.99 \pm 0.13{\mathrm{U} . \mathrm{mL}^{-1}}^{-1}(100 \%)$ at $28^{\circ} \mathrm{C}$ and dramatically decreased to $0.61 \pm 0.10$ U.mL $^{-1}(20$ $\%$ ) at $33^{\circ} \mathrm{C}$ (Figure $5 \mathrm{~B}$ ).

\subsection{Effect of Nutritional Parameters on CMCase Production}

\subsubsection{Effect of Inducer and its Concentration}

Peniophora sp. NDVN01 was grown on various complex lignocellulosic substrate sources at the concentration of $0.6 \%(w / v)$ to determine their effect on the induction of cellulolytic enzymes. Amongst all the tested substrates, pulp was found to be the best substrate for the CMCase production $\left(3.31 \pm 0.27 \mathrm{U} . \mathrm{mL}^{-1}\right)$, which is 5 times more effective than that $\left(0.6 \pm 0.06 \mathrm{U} \cdot \mathrm{ml}^{-1}\right)$ used CMC as substrate (Figure $6 \mathrm{~A}$ ). The CMCase production dramatically increased from $0.08 \pm 0.00 \mathrm{U}_{\mathrm{mL}}^{-1}(2 \%)$ at the concentration of $0.1 \%(\mathrm{w} / \mathrm{v})$ to $3.37 \pm 0.23 \mathrm{U} \cdot \mathrm{mL}^{-1}(100 \%)$, at the concentration of $0.5 \%(\mathrm{w} / \mathrm{v})$, the CMCase production has gradually decreased to $2.54 \pm 0.04 \mathrm{U}_{\mathrm{mL}} \mathrm{mL}^{-1}(75 \%)$ at the concentration of $0.8 \%(\mathrm{w} / \mathrm{v})$ and then rapidly dropped to $0.33 \pm 0.06 \mathrm{U}^{-1}(10 \%)$ at the concentration of $1 \%(\mathrm{w} / \mathrm{v})$ (Figure $6 \mathrm{~B}$ ).

\subsubsection{Effect of Potato Infusion}

Peniophora sp. NDVN01 produced the maximum amount of CMCase (6.95 U.mL ${ }^{-1}$ ) when cultured in the medium containing $80 \%(\mathrm{v} / \mathrm{v})$ of potato infusion and 0.5 $\%(\mathrm{w} / \mathrm{v})$ of pulp, at $28{ }^{\circ} \mathrm{C}, \mathrm{pH}$ 7. The CMCase production in the medium containing $10 \%(\mathrm{v} / \mathrm{v})$ of potato infusion was $2.28 \pm 0.08 \mathrm{U} \cdot \mathrm{mL}^{-1}(32 \%)$ and it gradually increased to 6.95 
\pm 0.15 U.mL ${ }^{-1}(100 \%)$ at the optimum concentration of 80 $\%$, then slowly decreased to $5.97 \pm 0.22 \mathrm{U}_{\mathrm{mL}}^{-1}(83 \%)$ in the medium containing of $100 \%$ of potato infusion (Figure 7 ).

\subsubsection{The Effect of Carbons Sources at Different Concentration}

In the culture medium containing $80 \%(\mathrm{v} / \mathrm{v})$ of potato infusion and $0.5 \%(\mathrm{w} / \mathrm{v})$ of pulp and $0.2 \%(\mathrm{w} / \mathrm{v})$ of another additional carbon source (Figure 8 A), Peniophora . NDVN01 had the highest amount of CMCase production $\left(7.02 \pm 0.21 \mathrm{U} . \mathrm{mL}^{-1}\right)$ in the medium containing rice straw (Figure $8 \mathrm{~A}$ ), which was two time higher than that $(3.48$ U.mL ${ }^{-1}$ ) in the control medium without any additional carbon source. The additional complex carbon source including sawdust, corncob, sugarcane bagasse, and CMC, slightly increased the CMCase production from 32 to 40 $\%$. But sugars as other additional carbon sources including glucose, mannose, lactose, and sucrose, decreased the CMCase production up to two thirds compared with the control medium. This might be explained that the strain preferred to consume simple sugar before utilizing other complex polysaccharides as cellulose.

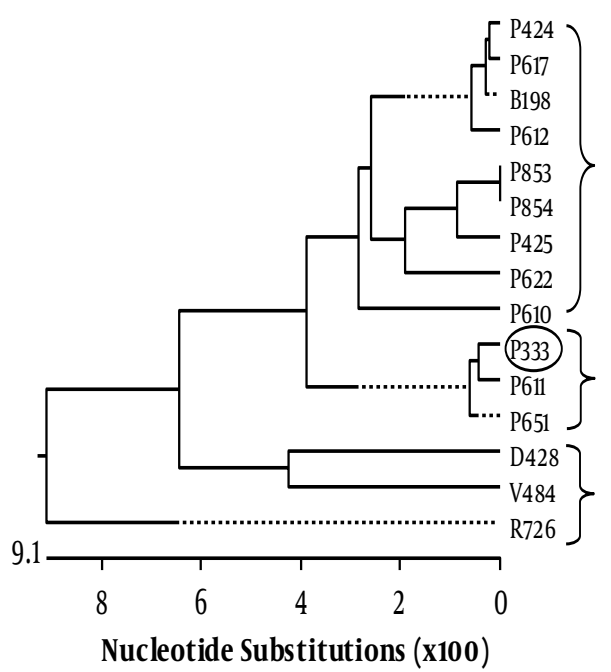

Figure 2. The phylogenetic dendrogram for the basidiomycete Peniophora sp. NDVN01 (P333: JF925333) and related fungal strains based on ITS sequence. Cf. Peniophora sp. MLB-2010 voucher UBC F19722 (HQ604853), Peniophora aurantiaca voucher UBC F19732 (HQ604854), Peniophora pini voucher Hjm 18143 (GB) (EU118651), Peniophora sp. TW06-13 (AB672622), uncultured Peniophora clone KL_2W_E07 (JF449617), Peniophora sp. M104-3B (HM595611), uncultured Basidiomycota clone bas07110 (HQ433198), Peniophora cinerea subsp. fagicola strain NH9808 (AF506424), Peniophora sp. M126-1 (HM595612), Peniophora incarnata strain NH10271(AF506425), Russuloid isolate BB1(AF283726), Peniophora sp. M161(HM595610), Vararia investiens strain TAA164122 (AF506484), Dichostereum aff.pallescens KHL10258(AF506428).

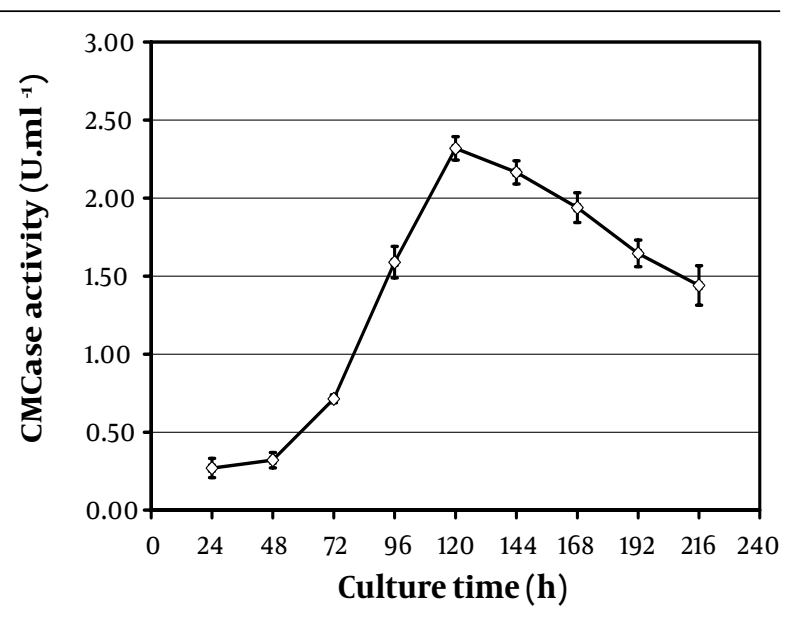

Figure 3. Time course of the CMCase production by Peniophora sp. NDVN01

The addition of rice straw dramatically increased the
CMCase production by Peniophora sp. NDVN01 from $5.97 \pm$ $0.26 \mathrm{U}^{\mathrm{mL}}{ }^{-1}(34 \%)$ in the medium containing $0.1 \%(\mathrm{w} / \mathrm{v})$ of rice straw to the maximum $17.37 \pm 0.48 \mathrm{U}_{\mathrm{mL}}^{-1}(100 \%)$ in the medium containing $0.6 \%(\mathrm{w} / \mathrm{v})$ of rice straw, and then gradually decreased to $5.46 \pm 0.95 \mathrm{U}_{\mathrm{mL}}{ }^{-1}(31 \%)$ in the medium containing $1.4 \%(\mathrm{w} / \mathrm{v})$ of rice straw (Figure $8 \mathrm{~B}$ ).

\subsubsection{Effect of Nitrogen Source and its Concentra- tion}

Among the tested nitrogen sources (Figure 9 A) added to the control medium, ammonium hydrogen phosphate increased the CMCase production by Peniophora sp. NDVN01 from $16.45 \pm 1.34$ U.mL $^{-1}$ in the control medium to $21.19 \pm 0.86 \mathrm{U}_{\mathrm{mL}} \mathrm{mL}^{-1}$. Fish meal and meat extract caused a slight decrease of 5-10 \% in CMCase production, but other nitrogen sources showed a strong effect on CMCase production, especially yeast extract decreased the CMCase production to $0.89 \pm 0$. U.mL ${ }^{-1}(5 \%)$ in com- 
parison to the control medium without addition of any extra nitrogen source. $0.2 \%(\mathrm{w} / \mathrm{v})$ ammonium hydrogen phosphate was optimal for the CMCase production by Peniophora sp. NDVN01 $\left(21.5 \pm 0.62{\mathrm{U} . \mathrm{mL}^{-1}}^{-1}\right)$ and more ammonium hydrogen phosphate decreased the CMCase production to $3.29 \pm 0.31 \mathrm{U}_{\mathrm{mL}}^{-1}(15 \%$ ) (Figure $9 \mathrm{~B}$ ).

\subsubsection{Effect of Mineral Sources and its Concentra- tion}

$\mathrm{KCl}$ and $\mathrm{CaCO}_{3}$ among the mineral sources were tested in this study that increased the CMCase production up to $12 \%$ but other mineral sources decreased the enzyme production (Figure $10 \mathrm{~A}$ ).

\subsection{CMCase Production under Optimal Conditions}

The CMCase production by Peniophora sp. NDVN01 in the optimum medium containing $80 \%(\mathrm{v} / \mathrm{v})$ of potato infusion, $0.5 \%(w / v)$ pulp, $0.1 \%(w / v) \mathrm{CaCO}_{3}$ and $0.15 \%(\mathrm{w} / \mathrm{v})$ $\mathrm{KCl}$, at $28^{\circ} \mathrm{C}$ and initial $\mathrm{pH}$ of 7 . for 120 hours was $24.65 \pm$ $0.37 \mathrm{U} \cdot \mathrm{mL}^{-1}$, that was 8.6 times more than that in the basal medium $\left(2.87 \pm 0.37 \mathrm{U}^{\mathrm{ml}}{ }^{-1}\right)$ (Figure 10 B).

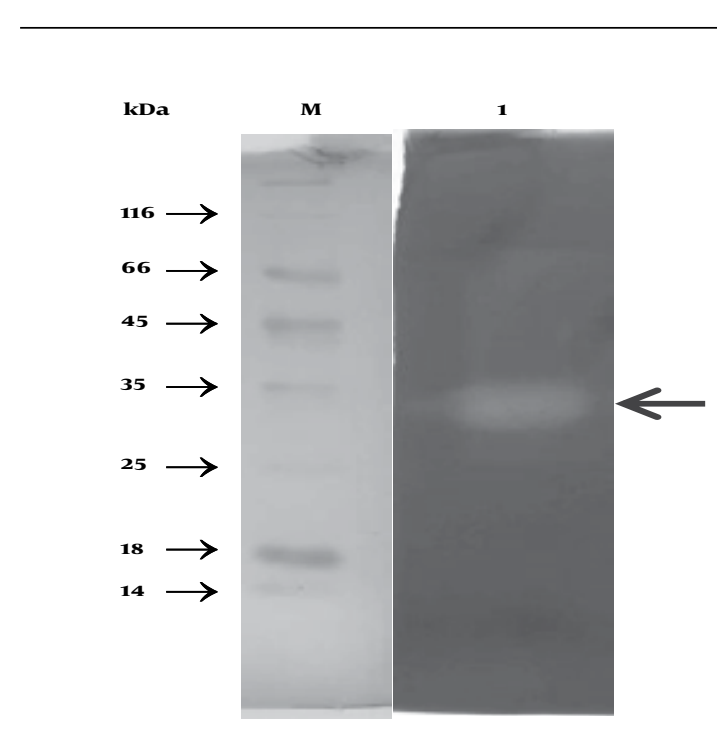

Figure 4. Native PAGE. Lane M, molecular mass ladder; lane 1, the culture supernatant stained with Congo Red.
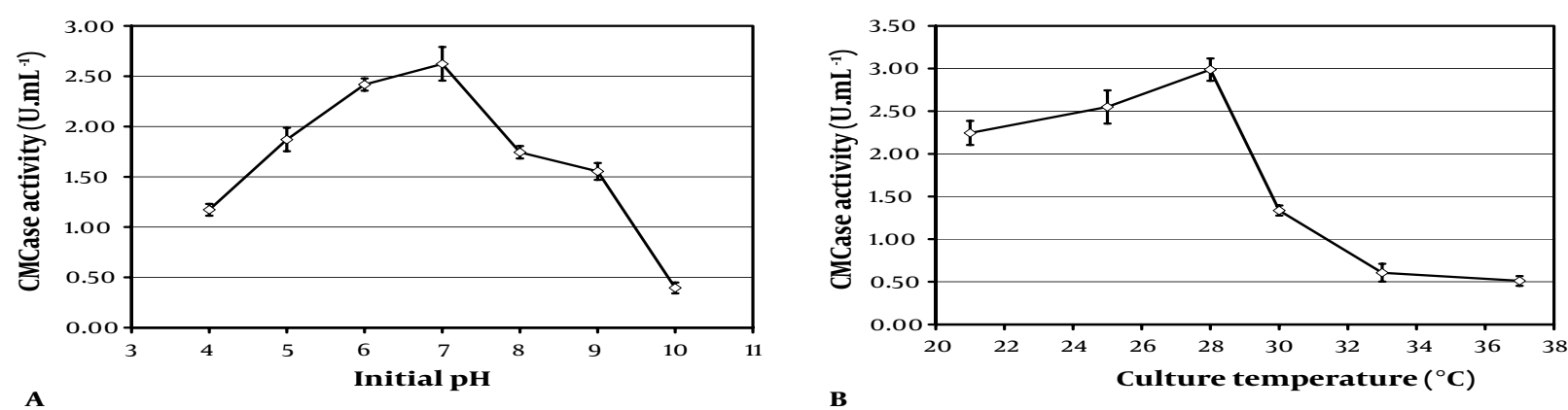

Figure 5. The effect of initial medium $\mathrm{pH}(\mathrm{A})$ and growth temperature (B) on the CMCase production by Peniophora sp. NDVN01.
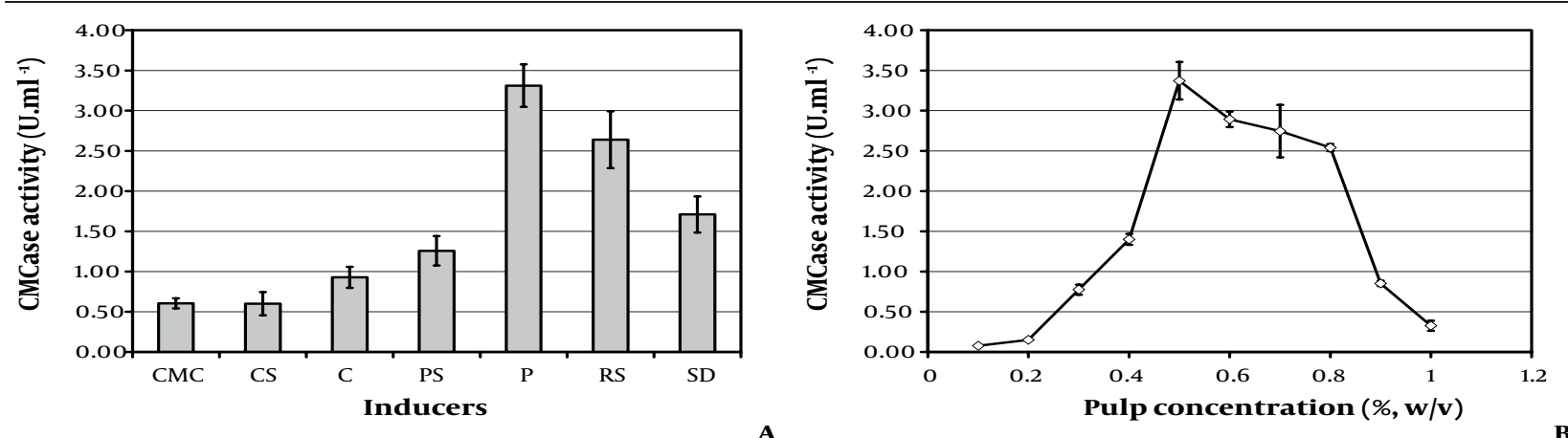

Figure 6. The relation of inducers (A) and pulp concentration (B) with CMCase production by Peniophora sp. NDVN01. (CMC: Carboxymethyl cellulose; CS: Coffee outerskin; C: Coir; PS: Peanut shells; P: Pulp; RS: rice straw; SB: Sugarcane bagasse; SD: Sawdust) 


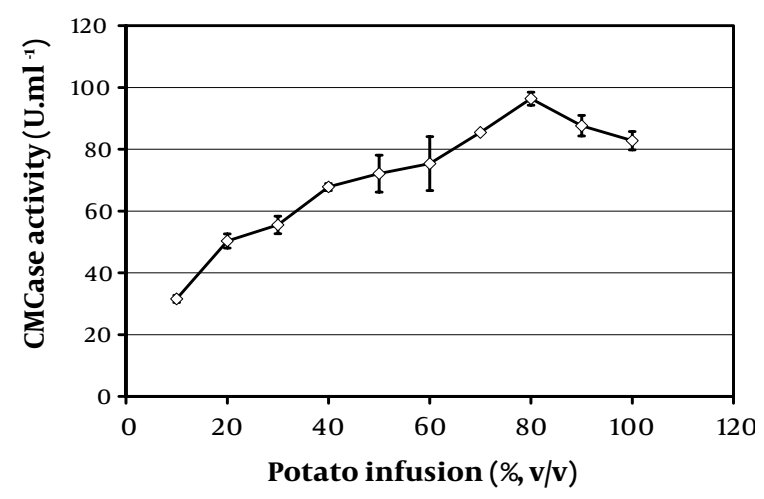

Figure 7. The effect of potato infusion concentration on the CMCase production by Peniophora NDVN01

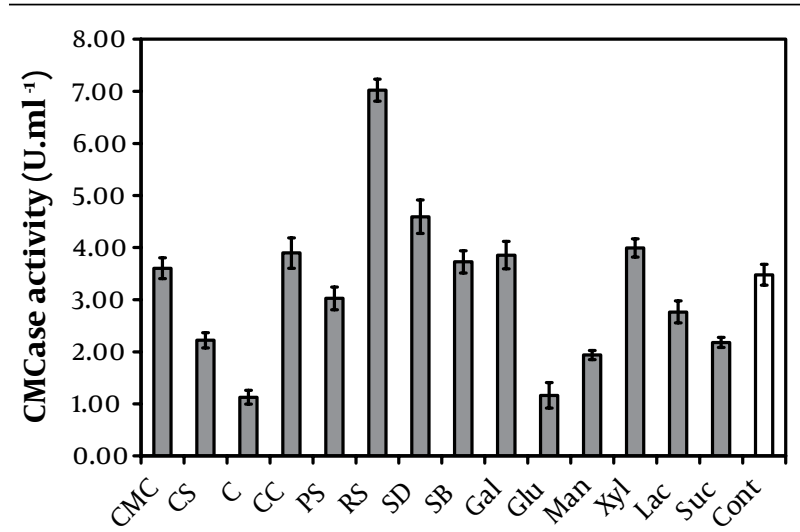

Carbon source

A

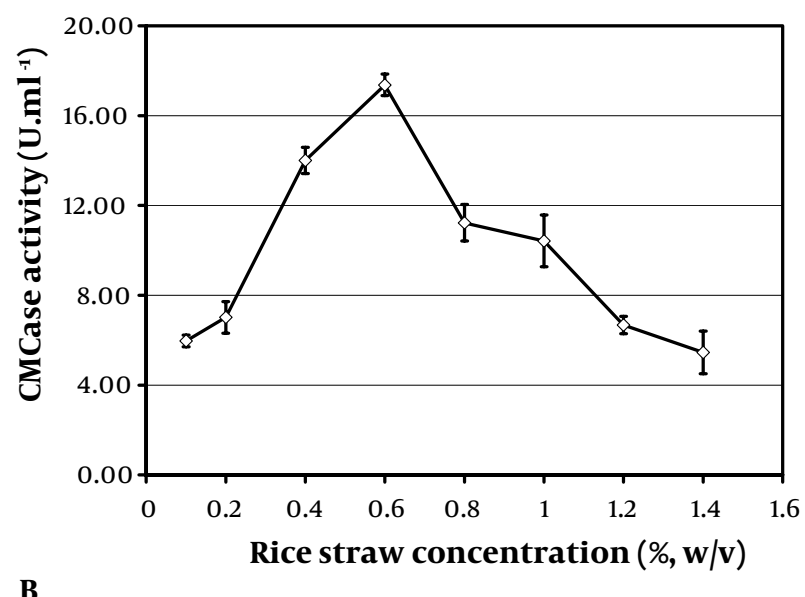

Figure 8. The effect of carbon sources (A) and concentration (B) on the CMCase production by Peniophora sp. NDVN01. (CMC: Carboxymethyl cellulose; CS: Coffee outerskin; C: Coir; CC: Corncob; PS: Peanut shells; RS: Rice straw; SB: Sugarcane bagasse; SD: Sawdust; Gal: Galactose; Glu: Glucose; Lac: Lactose; Man: Mannose; Suc: Sucrose; Xyl: xylose; Cont: Control)
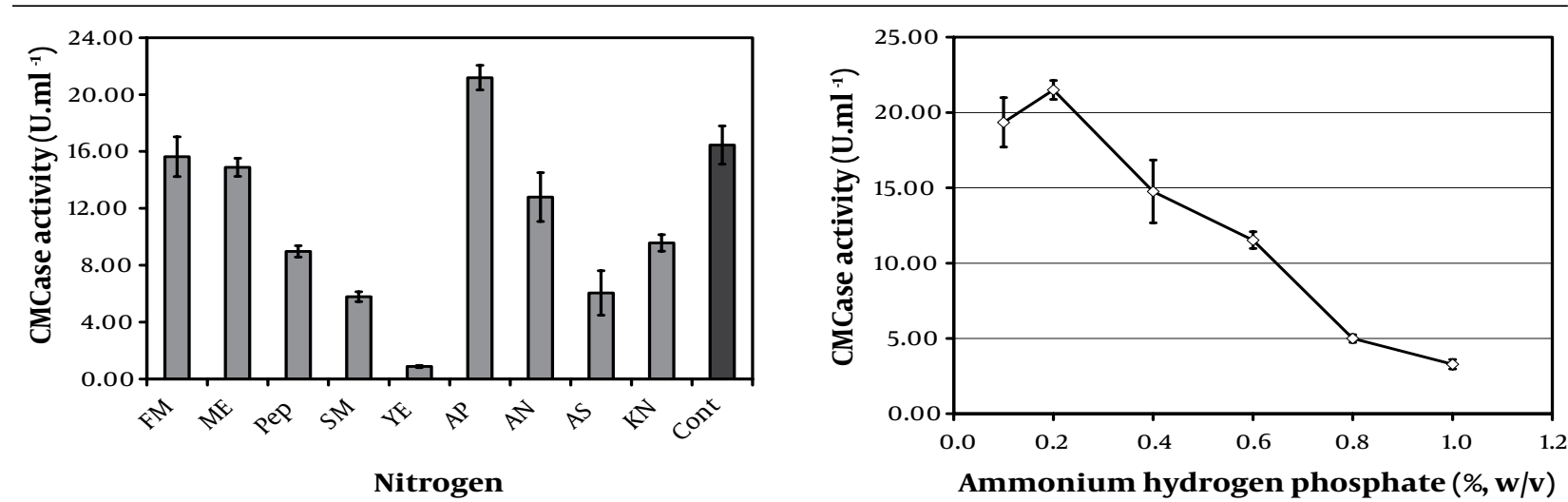

$\mathbf{A}$

B

Figure 9. The effect of nitrogen sources (A) and concentration (B) on the CMCase production by Peniophora sp. NDVN01. (FM: Fish meal; ME: Meat extract; Pep: Peptone; SM: Soybean meal; YE: Yeast extract; $\mathrm{AP}:\left(\mathrm{NH}_{4}\right)_{2} \mathrm{HPO}_{4} ; \mathrm{AN}: \mathrm{NH}_{4} \mathrm{NO}_{3} ; \mathrm{AS}:\left(\mathrm{NH}_{4}\right)_{2} \mathrm{SO}_{4}$; $\mathrm{KN}_{2} \mathrm{KNO}_{3}$; Cont: Control) 

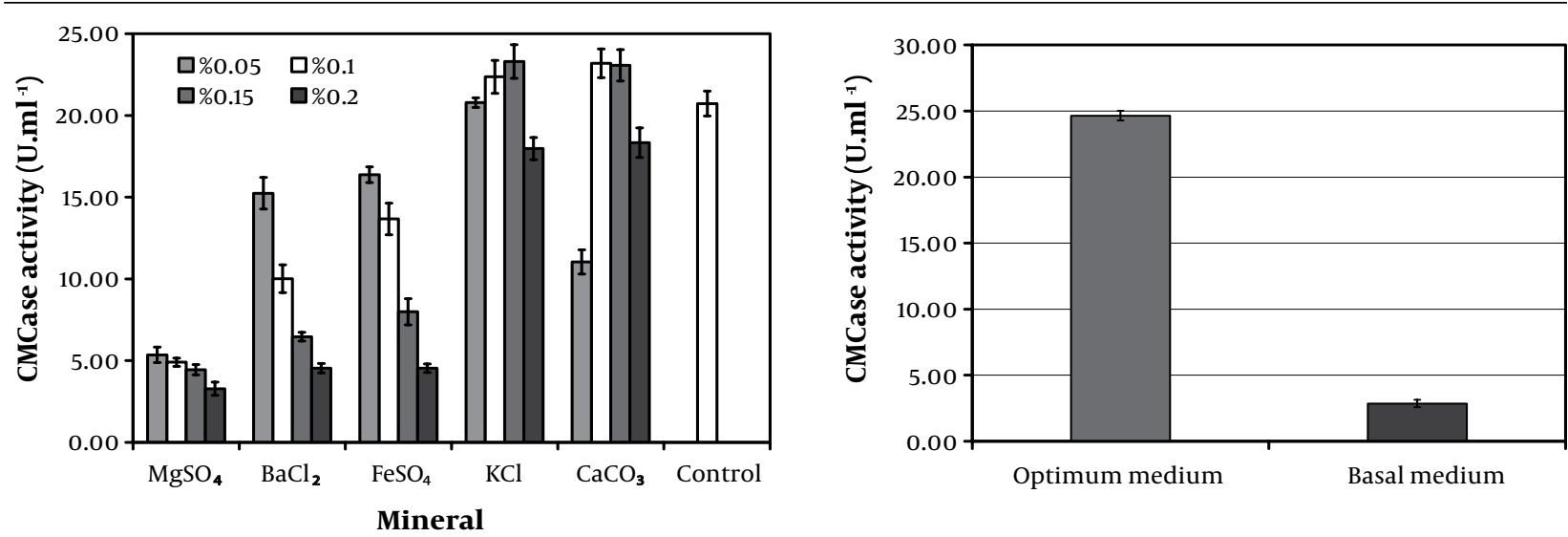

A

B

Figure 10. The effect of mineral sources on the CMCase production by Peniophora sp. NDVNO1 (A) and CMCase production in basal medium and optimal medium (B)

\section{Discussion}

The maximal CMCase production was obtained at least within 5 days by Peniophora sp. NDVN01 (in this study) and V. volvacea (12), within 6 days by Bjerkandera adusta UAMH 8258 (19) and V. volvacea (20), even longer within 8 days by Pycnoporus sanguineus CEIBMD01(19). In contrast, under solid-substrate culture conditions, basidiomycetes produced maximum amount of CMCase within 7 days by Peniophora sp. NDVN01 (21) or 11 days by Fomitopsis sp. RCK2010 (14).

The optimal $\mathrm{pH}$ for the CMCase production by Peniophora sp. NDVN01 was coincident with that in previous studies (21). Peniophora sp. NDVN01 produced maximum CMCase in solid-substrate culture at the initial $\mathrm{pH}$ of 7 (21), and two isolates of wood-decay basidiomycetes from the Sonoran Desert produced alkaline-active cellulases at optimal level when cultivated at $\mathrm{pH}$ 7. But other basidiomycetes B. adusta, P. sanguineus (19), V. volvacea (12) and Fomitopsis sp. RCK2010 (14) showed optimal CMCase production at lower initial medium $\mathrm{pH}$ of 5-6.

Most basidiomycetes including B. adusta, P. sanguineus (19), wood-decay basidiomycetes (22), Fomitopsis sp. RCK2010 (14) and Peniophora sp. NDVN01 (21) and also in this study produced maximum CMCase at a moderate temperature from 27 to $30{ }^{\circ} \mathrm{C}$. But the fungus $V$. volvacea showed maximum CMCase production at higher temperature, specifically at $37^{\circ} \mathrm{C}(12)$.

In this study, amongst all tested inducers, pulp was found to be the inducer for the maximum amount of CMCase production. In contrast, paper pulp did support neither growth nor enzyme production by two Sonoran Desert basidiomycetes (22). Other studies reported that Avicel microcrystalline cellulose showed the highest induction of CMCase production by V. volvacea (12).

Different basidiomycetes used different carbon sources for maximum CMCase production. Under solid state fermentation, Peniophora sp. NDVNo1 (21) and Fomitop- sis sp. RCK2010 (14) produced maximum CMCase using corncob and wheat bran as carbon source, respectively. Under liquid state fermentation, for the highest CMCase production, Peniophora sp. NDVN01 (in this study), two basidiomycetes from the Sonoran Desert (22), Phlebia gigantea (23), Fomes fomentarius IBB, Pleurotus ostreatus IBB 10, Pseudotremella gibbosa IBB 22 (24) used rice straw, wheat bran, carboxymethyl cellulose, residue of ethanol production from wheat grains, peach pomace, and mandarin peels as inducers, respectively. In general, sugars as carbon sources decreased the CMCase production by Peniophora sp. NDVN01 (in this study) and P. gigantea (23) since in presence of these simple carbohydrates, the cellulose production was repressed.

Peniophora sp. NDVN01 showed the maximum CMCase production in the medium containing ammonium hydrogen phosphate under liquid state fermentation (in this study) as well as under solid state fermentation (21). Fomitopsis sp. RCK2010 (14) produced maximum CMCase in the medium containing urea under solid state fermentation.

Metal ions $\mathrm{K}^{+}$and $\mathrm{Ca}^{2+}$ seemed to be important for the CMCase production by Peniophora sp. NDVN01 but $\mathrm{Mg}^{2+}$, $\mathrm{Fe}^{2+}$ and $\mathrm{Ba}^{2+}$ repressed the enzyme production which was also found for enzyme production by Rhizopus oryzae (25).

The basidiomycete isolate NDVN01 was identified as Peniophora sp. NDVN01 and produced a CMCase with a molecular mass of 32-33 $\mathrm{kDa}$ at maximum level when grown at $28{ }^{\circ} \mathrm{C}$, with the initial pH of 7 within 120 hours of cultivation in the optimal medium containing $80 \%$ $(\mathrm{v} / \mathrm{v})$ of potato infusion, $0.6 \%$ rice straw as additional carbon source and $0.2 \%(\mathrm{w} / \mathrm{v})\left(\mathrm{NH}_{4}\right)_{2} \mathrm{HPO}_{4}$ as additional nitrogen source, and $0.5 \%(\mathrm{w} / \mathrm{v})$ pulp as inducer. Under the optimal conditions, the amount of CMCase produced by Peniophora sp. NDVN01 $\left(24.65 \pm 0.37\right.$ U.mL $\left.{ }^{-1}\right)$ was 8.6 times higher than the amount before optimiza- 
tion $\left(2.87 \pm 0.28 \mathrm{U}_{\mathrm{mL}}^{-1}\right)$.

\section{Acknowledgements}

There are no acknowledgments.

\section{Authors' Contribution}

DTQ designed, provided consultation, supervised the study, analyzed data and wrote the manuscript. DKT performed the experiments, analyzed data and wrote the manuscript. TTHN performed experiments. TTD and NMN provided consultation.

\section{Financial Disclosure}

There is no financial disclosure.

\section{Funding / Support}

The study was supported by the Master Program of Development and Application of Biotechnology in Agriculture and Rural Development Towards 2020, Vietnam Ministry of Agriculture and Rural Development (Project: Production and application of highly qualitative multienzyme products by recombinant microbes to improve the effective use of animal feed, 2007-2010).

\section{References}

1. Festucci-Buselli RA, Wagner CO, Chandrashekhar PJ. Structure, organization, and functions of cellulose synthase complexes in higher plants. Braz J Plant Physiol. 2007;19:1-13.

2. Bhat MK, Bhat S. Cellulose degrading enzymes and their potential industrial applications. Biotechnol Adv. 1997;15(3 - 4):583-620.

3. Olofsson K, Wiman M, Liden G. Controlled feeding of cellulases improves conversion of xylose in simultaneous saccharification and co-fermentation for bioethanol production. J Biotechnol. 2010;145(2):168-75.

4. Jabbar A, Rashid MH, Javed MR, Perveen R, Malana MA. Kinetics and thermodynamics of a novel endoglucanase (CMCase) from Gymnoascella citrina produced under solid-state condition. J Ind Microbiol Biotechnol. 2008;35(6):515-24.

5. Himmel ME, Ruth MF, Wyman CE. Cellulase for commodity products from cellulosic biomass. Curr Opin Biotechnol. 1999;10(4):358364.

6. Han W, He M. The application of exogenous cellulase to improve soil fertility and plant growth due to acceleration of straw decomposition. Bioresour Technol. 2010;101(10):3724-31.

7. Bhat MK. Cellulases and related enzymes in biotechnology. Biotechnol Adv. 2000;18(5):355-383.

8. Dürre P. New insights and novel developments in clostridial acetone / butanol / isopropanol fermentation. Appl Microbiol Biotechnol.1998;49(6):639-648.

9. Ahamed A, Vermette P. Culture-based strategies to enhance cellulase enzyme production from Trichoderma reesei RUT-C30 in bioreactor culture conditions. Biochem EngJ. 2008;40(3):399-407.
10. Kalogeris E, Christakopoulos P, Katapodis P, Alexiou A, Vlachou $\mathrm{S}$, Kekos D, et al. Production and characterization of cellulolytic enzymes from the thermophilic fungus Thermoascus aurantiacus under solid state cultivation of agricultural wastes. Process Biochem. 2003;38(7):1099-1104.

11. Kuhad RC, Singh A, Eriksson KEL, Eriksson KEL, Babel W, Blanch HW, Cooney ChL, Enfors SO, Fiechter A, et al. Microorganisms and enzymes involved in the degradation of plant fiber cell walls. In: Kuhad RC, Singh A, Eriksson KEL, Eriksson KEL, Babel W, Blanch HW, Cooney ChL, Enfors SO, Fiechter A, et al, editors.Springer Berlin Heidelberg; 1997. p. 45-125.

12. Chang SC, Steinkraus KH. Lignocellulolytic enzymes produced by Volvariella volvace, the edible straw mushroom. Appl Environ Microbiol.1982;43(2):440-6.

13. Ding SJ, Ge W, Buswell JA. Endoglucanase I from the edible straw mushroom, Volvariella volvacea. Purification, characterization, cloning and expression. Eur J Biochem. 2001;268(22):5687-95.

14. Deswal D, Khasa YP, Kuhad RC. Optimization of cellulase production by a brown rot fungus Fomitopsis sp. RCK2010 under solid state fermentation. Bioresour Technol. 2011;102(10):6065-72.

15. Yoon JJ, Cha CJ, Kim YS, Kim W. Degradation of cellulose by the major endoglucanase produced from the brown-rot fungus Fomitopsis pinicola. Biotechnol Lett. 2008;30(8):1373-8.

16. Yoon JJ, Kim YK. Degradation of crystalline cellulose by the brown-rot basidiomycete Fomitopsis palustris. J Microbiol. 2005;43(6):487-92.

17. Kapoor S, Khanna PK, Katyal P. Effect of supplementation of Wheat straw on growth and lignocellulolytic enzyme potential of Lentinus edodes. WJAS. 2009;5:328-31.

18. Dias AA, Freitas GS, Marques GS, Sampaio A, Fraga IS, Rodrigues MA, et al. Enzymatic saccharification of biologically pretreated wheat straw with white-rot fungi. Bioresour Technol. 2010;101(15):6045-50.

19. Quiroz-Casta-eda RE, Balcázar-López E, Dantán-González E, Martinez A, Folch-Mallol J, Anaya CM. Characterization of cellulolytic activities of Bjerkandera adusta and Pycnoporus sanguineus on solid wheat straw medium. Electron J Biotechnol. 2009;12:1-8.

20. Cai YJ, Chapman SJ, Buswell JA, Chang ST. Production and distribution of endoglucanase, cellobiohydrolase, and betaglucosidase components of the cellulolytic system of Volvariella volvacea, the edible straw mushroom. Appl Environ Microbiol. 1999;65(2):553-9.

21. Trinh DK, Quyen DT, Nghiem NM. Optimization of carboxymethyl cellulase production by a basidiomycete Peniophora sp. NDVN01 under solid state fermentation. Vietn J Biotechnol. 2011;9:845-52.

22. Sreenath HK, Yang VW, Burdsall JHH, Jeffries TW. Toner removal by alkaline-active cellulases from desert basidiomycetes. In: Jeffries TW, Viikari L, editors. Enzymes for pulp and paper processing ACS Symposium Series 655 Proceedings, 211th ACS national meeting of the Cellulose, Paper, and Textile Division;1996, March 24-28; New Orleans, LA. Washington, DC: American Chemical Society. 1996. 267-79.

23. Niranjane AP, Madhou P, Stevenson TW. The effect of carbohydrate carbon sources on the production of cellulase by Phlebia gigantea. Enzyme Microb Technol. 2007;40(6):1464-1468.

24. Elisashvili V, Kachlishvili E, Tsiklauri N, Metreveli E, Khardziani $\mathrm{T}$, Agathos SN. Lignocellulose-degrading enzyme production by white-rot Basidiomycetes isolated from the forests of Georgia. World J Microbiol Biotechnol. 2009;25(2):331-339.

25. Karmakar M, Ray RR. Production of extra cellular endoglucanase by hyper productive pellets of Rhizopus oryzae. World J Sci Technol. 2011;1:26-32. 